\title{
Physical Properties of Rice Residues as Affected by Variety and Climatic and Cultivation Onditions in Three Continents
}

\author{
${ }^{1,2}$ Yaning Zhang, ${ }^{1}$ A.E. Ghaly and ${ }^{2}$ Bingxi Li \\ ${ }^{1}$ Department of Process Engineering and Applied Science, \\ Faculty of Engineering, Dalhousie University, Halifax, Canada \\ ${ }^{2}$ School of Energy Science and Engineering, Harbin Institute of Technology, Harbin, China
}

Received 2012-08-16, Revised 2012-08-29; Accepted 2012-08-29

\begin{abstract}
Rice husk and straw are by-products of rice cultivation and processing industry and can be used as an energy source. Proper understanding of the physical properties of rice residues is necessary for utilizing them in thermochemical conversion processes such as gasification and combustion. The physical properties (moisture content, particle size, bulk density and porosity) of rice husks and straws obtained from three countries (Egypt, Cuba and China) were evaluated in this study. The moisture contents of rice husks and straws were in the ranges of $4.60-6.07 \%$ and $6.58-6.92 \%$, respectively. For all rice varieties tested, the moisture content of the straws was higher than these of the husks. The particle sizes of rice husks and straws were in the ranges of $0.212-0.850 \mathrm{~mm}$ and $0-0.710 \mathrm{~mm}$, respectively. All the rice husk varieties had a normal distribution of particle size around the main value of $0.6 \mathrm{~mm}$ while the particle size distribution for the rice straws showed a decreasing trend, the larger the particle size the higher was the weight percentage. The bulk density of rice husks and straws were in the ranges of $331.59-380.54 \mathrm{~kg} \mathrm{~m}^{-3}$ and $162.03-194.48 \mathrm{~kg} \mathrm{~m}^{-3}$, respectively. The bulk density values of rice straws were lower than those of rice husks. A negative linear relationship between the bulk density and the average particle size was observed for rice husks and straws. The porosity of rice husks and straws were in the ranges of $63.64-68.94 \%$ and $71.21-85.28 \%$, respectively. A positive linear relationship between the porosity and the average particle size was observed for rice husks and straws. Also, a negative linear relationship between the porosity and the bulk density was observed. The results obtained from this study showed significant differences in the physical properties of the rice husks and straws collected from different countries (located in three different continents). These differences may be due to variations in climatic conditions, soil type, methods of cultivation and type of fertilizer used. The results also indicated that different parts of rice plant (straw and husk) had different physical properties. Also, significant differences were observed among rice varieties even though they were grown under the same climatic conditions using same soil type and cultivation method as in the case of the long and short grain rice variety of Egypt.
\end{abstract}

Keywords: Bulk Density, Particle Size, Porosity, Moisture Content, Variety, Straw, Rice Husk

\section{INTRODUCTION}

Rice is a staple food of over half the world's population and about one-fifth of the world's population is engaged in rice cultivation (Reidy, 2011). The global paddy rice production continued to increase at an average rate of 16.48 million tonnes per year during the last ten years (Fig. 1), reaching about 718.3 million tonnes in 2011 (FAO, 2011), with an estimated value of US\$ 240 billion. Table 1 shows the rice production and yield for the important rice producing countries. China, Egypt and Cuba (countries used in this study) contribute $27.51,0.63$ and $0.07 \%$ to the global rice production and are ranked 1th, 16th and 39 th, respectively. The per capita rice production, rice consumption and rice exports of the top 10 counties are presented in Fig. 2-4, respectively. Rice is the world's second largest cereal crop and produces the largest amount of crop residues (Soest, 2006). Rice, rice husk and rice straw are the main products of rice cultivation and processing (Binod et al., 2010). The average ratio of rice grain: rice husk: rice straw is 1:0.25:1.25 (Haefele et al., 2011). Corresponding Author: Ghaly, A.E., Department of Process Engineering and Applied Science, Faculty of Engineering, Dalhousie University, Halifax, Canada 
Table 1. Word paddy rice production (FAO, 2011; USDA, 2011; GS, 2011)

\begin{tabular}{|c|c|c|c|c|}
\hline \multirow[b]{2}{*}{ Country } & \multicolumn{4}{|c|}{ Rice production } \\
\hline & $\begin{array}{l}\text { Weight } \\
\text { (million } \\
\text { tonnes) }\end{array}$ & $\begin{array}{l}\text { Percentage } \\
(\%)^{\mathrm{a}}\end{array}$ & $\begin{array}{l}\text { Yield } \\
\text { (tonnes } \\
\left.\mathrm{ha}^{-1}\right)\end{array}$ & $\begin{array}{l}\text { Per capita } \\
\text { (tonnes } \\
\text { person }^{-1} \text { ) }\end{array}$ \\
\hline China & 197.6 & 27.51 & 6.60 & 0.147 \\
\hline India & 150.0 & 20.88 & 3.33 & 0.121 \\
\hline Indonesia & 68.1 & 9.48 & 5.60 & 0.281 \\
\hline Bangladesh & 51.6 & 7.18 & 4.30 & 0.343 \\
\hline Viet Nam & 41.0 & 5.71 & 5.43 & 0.462 \\
\hline Thailand & 35.0 & 4.87 & 3.19 & 0.503 \\
\hline Myanmar & 31.0 & 4.32 & 4.64 & 0.641 \\
\hline Philippines & 17.3 & 2.41 & 3.76 & 0.182 \\
\hline Brazil & 13.7 & 1.91 & 5.27 & 0.700 \\
\hline Japan & 10.3 & 1.43 & 6.54 & 0.081 \\
\hline Pakistan & 10.0 & 1.39 & 3.64 & 0.057 \\
\hline Cambodia & 8.5 & 1.18 & 3.15 & 0.549 \\
\hline United States & 8.5 & 1.18 & 8.03 & 0.027 \\
\hline Rep. Korea & 6.0 & 0.84 & 7.03 & 0.124 \\
\hline Madagascar & 4.7 & 0.65 & 3.51 & 0.221 \\
\hline Egypt & 4.5 & 0.63 & 5.92 & 0.055 \\
\hline Nigeria & 4.3 & 0.60 & 1.98 & 0.026 \\
\hline Sri Lanka & 4.2 & 0.59 & 3.85 & 0.201 \\
\hline Lao & 3.1 & 0.43 & 3.78 & 0.493 \\
\hline Peru & 2.7 & 0.38 & 7.94 & 0.092 \\
\hline Iran & 2.5 & 0.35 & 4.63 & 0.033 \\
\hline Dem. Korea & 2.5 & 0.35 & 4.39 & 0.102 \\
\hline Colombia & 2.5 & 0.35 & 5.32 & 0.033 \\
\hline Mali & 2.4 & 0.33 & 3.36 & 0.148 \\
\hline Argentina & 1.7 & 0.24 & 7.17 & 0.042 \\
\hline Uruguay & 1.7 & 0.23 & 9.71 & 0.488 \\
\hline Italy & 1.6 & 0.22 & 6.00 & 0.026 \\
\hline Taiwan & 1.5 & 0.21 & 5.75 & 0.066 \\
\hline Ghana & 1.5 & 0.21 & 9.06 & 0.062 \\
\hline Rep.Tanzania & 1.4 & 0.19 & 2.00 & 0.030 \\
\hline Ecuador & 1.4 & 0.19 & 4.00 & 0.095 \\
\hline Sierra Leone & 1.2 & 0.17 & 1.78 & 0.200 \\
\hline Venezuela & 1.1 & 0.15 & 7.86 & 0.037 \\
\hline Russia & 1.1 & 0.15 & 5.24 & 0.008 \\
\hline Spain & 1.0 & 0.13 & 7.00 & 0.020 \\
\hline Dominican & 0.9 & 0.13 & 4.89 & 0.089 \\
\hline Australia & 0.8 & 0.11 & 7.99 & 0.036 \\
\hline Bolivia & 0.6 & 0.08 & 3.74 & 0.057 \\
\hline Cuba & 0.5 & 0.07 & 2.55 & 0.045 \\
\hline Others & 15.2 & 2.12 & - & - \\
\hline
\end{tabular}

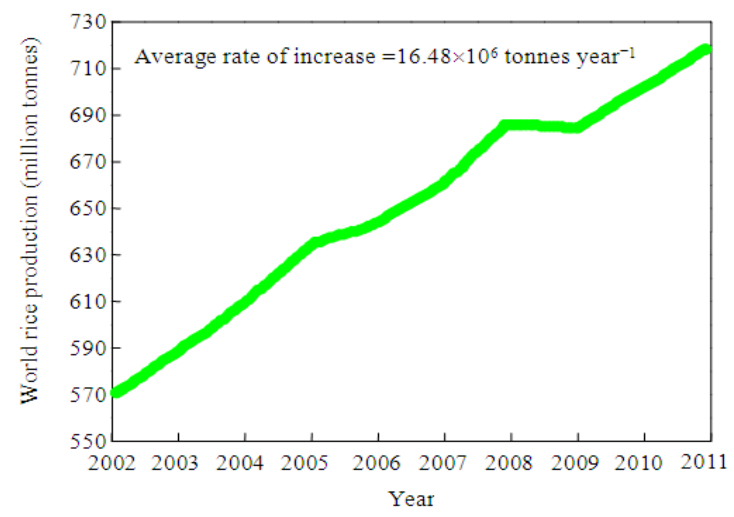

Fig. 1. World rice production and trend (FAO, 2011)

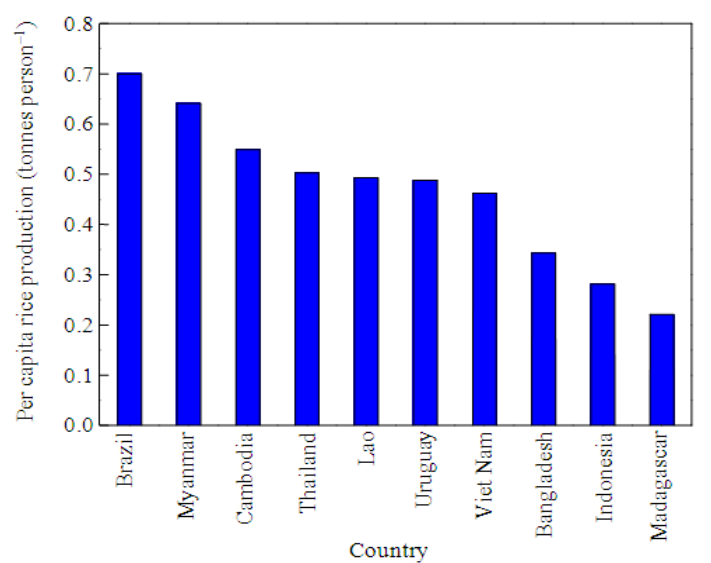

Fig. 2. Per capita rice production of the top 10 countries (FAO, 2011; GS, 2011)

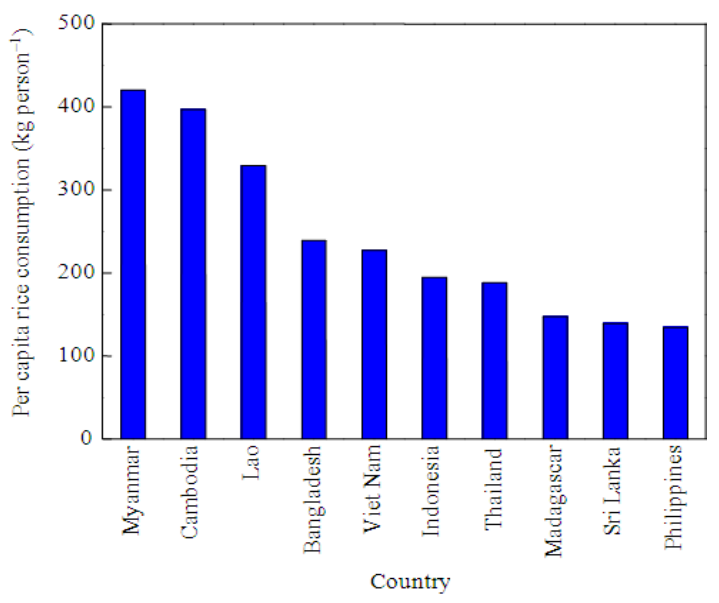

Fig. 3. Per capita rice consumption of the top 10 countries (FAO, 2011; GS, 2011)

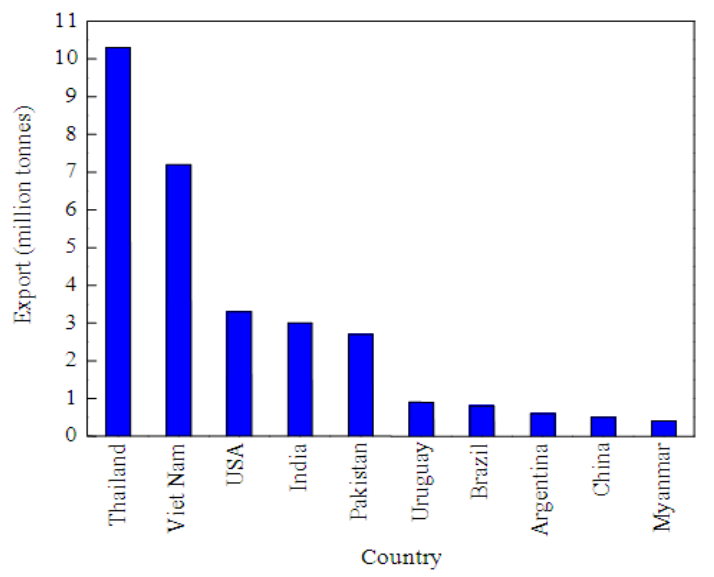

Fig. 4. Rice exports by the top 10 countries (FAO, 2011) 
Currently, the two rice residues (husk and straw) have limited applications. Rice husk can be used as a fertilizer while rice bran can be used as an animal feed (Vadiveloo et al., 2009) and rice straw is used as a roughage in animal feeding (Dong et al., 2008).

However, most of the rice straws are burnt in the field causing significant environmental and health problems as well as serious traffic accidents in addition to the loss of valuable resource (Chou et al., 2009). Rice residues are abundantly available and renewable and can be used as an energy source in thermochemical conversion processes such as gasification and combustion (Yoon et al., 2012; Delivand et al., 2011) or in bioconversion processes for production of bioethanol (Karimi et al., 2006) and biogas (Teghammar et al., 2012). The ash produced from gasification and combustion processes can be used as a supplementary material in cement and ceramic manufacturing (Zain et al., 2011) and the spent material from bioconversion can be used as an animal feed (Bisaria et al., 1997).

The physical properties of biomass materials such as rice husk and straw influence the design and operation of thermochemical conversion systems. High moisture content decreases the heating value of fuel, which in turn reduces the conversion efficiency as a large amount of energy would be used for initial drying step during the conversion processes (Mansaray and Ghaly, 1997). Particle size distribution substantially affects the flowability of material and other properties such as heating, diffusion and rate of reaction (Guo et al., 2012; Hernández et al., 2010). The bulk density of rice residues makes the collection, transportation and storage economically unattractive (Natarajan et al., 1998). It also makes feeding the material into the thermochemical conversion system difficult. Porosity changes the interstitial airflow velocity and the heat and mass transfer conditions and ultimately influences combustion parameters such as heat conductivity, burning rate, conversion efficiency and emissions (Igathinathane et al., 2010; Hamel and Krumm, 2008). Therefore, full understanding of the physical properties of rice residues is essential for the design and operation of efficient thermochemical conversion systems such as gasifiers and combustors. The main objectives of this study were: (a) to investigate the physical properties (moisture content, particle size distribution, bulk density and porosity) of rice residues (husk and straw) obtained from three different continents (Africa, south America and Asia) as related to pre-processing and design of thermochemical conversion systems, (b) to compare the physical properties of husks and straws and (c) to determine the effect of rice variety and climatic and cultivation conditions on the physical properties of rice husks and straws obtained from different countries (Egypt, Cuba and China) in these continents.

\section{MATERIALS AND METHODS}

\subsection{Sample Collection}

The rice residues (husks and straws) from four varieties of rice were used in this study. Long grain rice husk and straw and short grain rice husk and straw were obtained from Egypt. Cascara de arroz rice husk and straw were obtained from Cuba. Japonica rice husk and straw were obtained from China. The rice production, climatic and soil conditions and rice cultivation methods for Egypt, Cuba and China are shown in Table 2.

\subsection{Sample Preparation}

Rice residues were ground through a coarse sieve (12.7 $\mathrm{mm})$ and a 20 -mesh sieve $(0.85 \mathrm{~mm})$ on a medium size Wiley Mill (Model X876249, Brook Crompton Parkinson Limited, Toronto, Ontario). The coarse ground samples were then reground through a 40 -mesh sieve $(0.425 \mathrm{~mm})$ on the Wiley Mill in order to narrow the range of particle size and thus obtain homogeneous samples.

\subsection{Moisture Content}

Moisture content was determined using the ovendrying method (ASTM 2010). A large aluminum dish was weighed using a digital balance (Model PM 4600, Mettler Instrument AG, Greifensee, Zurich). The ground sample was placed in the dish and the dish and sample were weighed. The dish and sample were then placed in an air-forced drying oven (Heratherm, Thermo Fisher Scientific Inc., Waltham, USA) and kept at $105^{\circ} \mathrm{C}$ until a constant weight was achieved. The dish containing the dried sample was cooled to the room temperature in a desiccator and then weighed. The moisture content was calculated on a wet basis as follows Equation 1:

$$
\mathrm{MC}=\frac{\mathrm{WW}-\mathrm{DW}}{\mathrm{WW}} \times 100
$$

Where:

MC = The moisture content (\%)

$\mathrm{WW}=$ The wet weight of the sample and dish $(\mathrm{g})$

DW $=$ The dry weight of the sample and dish (g)

\subsection{Particle Size Distribution}

The particle size distribution was determined using seven standard sieves (Canadian Standard Sieve Series, W.S. Tyler Company of Canada Limited, St. Catharines, Ontario) and a bottom pan that collected everything that passes though the seventh sieve. The sieves were mounted on an electrical sieve shaker driven by a $0.25-$ $\mathrm{hp}$ electric motor running at $1725 \mathrm{rpm}$ (Model Rx-86, Hoskin Scientific Limited, Gastonia, North Carolina). 
Table 2. Rice production, climatic and soil conditions and cultivation methods for Egypt, Cuba and China

\begin{tabular}{|c|c|c|c|}
\hline Parameter & Egypt & Cuba & China \\
\hline Rice yield $\left(\mathrm{t} \mathrm{ha}^{-1}\right)$ & 5.92 & 2.55 & 6.60 \\
\hline Rice production ${ }^{a}$ & 3.60 & 0.40 & 158.08 \\
\hline Husk $^{\mathrm{a}}$ & 0.90 & 0.10 & 39.52 \\
\hline Straw ${ }^{a}$ & 4.50 & 0.50 & 197.60 \\
\hline Precip. $\left(\mathrm{mm} \mathrm{y}^{-1}\right)$ & 26 & 1243 & 619 \\
\hline Min Tem. $\left({ }^{\circ} \mathrm{C}\right)$ & 9 & 18 & -10 \\
\hline Max Tem. $\left({ }^{\circ} \mathrm{C}\right)$ & 35 & 32 & 31 \\
\hline Average $\left({ }^{\circ} \mathrm{C}\right)^{\mathrm{b}}$ & 23.67 & 24.33 & 22.50 \\
\hline Soil type & Alluvial & Luvisols & Black soil \\
\hline Fertilizer & $\mathrm{N}$ & Ammonium & Urea \\
\hline Planting time & $4-5$ & $4-7$ & $5-6$ \\
\hline Harvesting time & $9-11$ & $10-12$ & $8-9$ \\
\hline Growing duration $^{\mathrm{c}}$ & $110-160$ & $118-140$ & $120-140$ \\
\hline $\begin{array}{l}\text { Cultivation } \\
\text { method }\end{array}$ & Transplanting & Direct seeding & Transplanting \\
\hline
\end{tabular}

Table 3. Sieve number, mesh number and mesh size

\begin{tabular}{lll}
\hline Sieve number & Mesh number & Mesh size $(\mathrm{mm})$ \\
\hline 1 & 20 & 0.850 \\
2 & 25 & 0.710 \\
3 & 35 & 0.500 \\
4 & 40 & 0.425 \\
5 & 45 & 0.355 \\
6 & 50 & 0.300 \\
7 & 70 & 0.212 \\
pan & - & 0.000 \\
\hline
\end{tabular}

A sample weighed $250 \mathrm{~g}$ was placed in sieve 1 , which was then covered with the sieve lid. The shaker was operated at the speed of $350 \mathrm{rpm}$ for 30 minutes. The particles collected in each sieve were weighed. The sieve number, mesh number and mesh size of the seven sieves are shown in Table 3.

\subsection{Bulk Density}

An empty container $(150 \mathrm{~mL})$ was weighed using a digital Mettler balance (Model PM 4600, Mettler Instrument AG, Greifensee, Zurich) to the nearest $0.0001 \mathrm{~g}$. The container was filled with the sample and the material was slightly compacted to ensure absence of large void spaces. The container and the sample were then weighed. Three replicates were carried out. The wet bulk density of the sample was calculated from the following Equation 2:

$\rho_{\mathrm{b}}=\frac{\left(\mathrm{W}_{2}-\mathrm{W}_{1}\right)}{\mathrm{V}}$

Where:

$\rho_{\mathrm{b}}=$ The bulk density of the sample $\left(\mathrm{g} \mathrm{cm}^{-3}\right)$

$\mathrm{W}_{2}=$ The weight of the container and sample $(\mathrm{g})$

$\mathrm{W}_{1}=$ The weight of the container $(\mathrm{g})$

$\mathrm{V}=$ The volume of the container $\left(\mathrm{cm}^{3}\right)$

\subsection{Porosity}

The porosity of biomass was determined using the water pycnometer method. A sample of approximately $33 \mathrm{~mL}$ was placed in a $100 \mathrm{~mL}$ graduated cylinder. A wire mesh screen was placed on the top of the sample to prevent material from floating once submerged in water. Distilled water was slowly poured over the sample until the water level was above the top of the sample. The cylinder was gently rocked from side to side ten times to free trapped air bubbles before recording the final water level. The amount of added water and the water level were recorded to the nearest $1 \mathrm{~mL}$. The cylinder was emptied and cleaned thoroughly after each test. Three replicates were carried out. The porosity of biomass was calculated from the following Equation 3:

$P(\%)=\frac{V_{i}-V_{f}}{V_{s}} \times 100$

Where:

$\mathrm{P}=$ The porosity of the sample (\%)

$\mathrm{V}_{\mathrm{i}}=$ The combined volume of the sample plus added water $(\mathrm{mL})$

$\mathrm{V}_{\mathrm{f}}=$ The final total volume of the sample and added water $(\mathrm{mL})$

$\mathrm{V}_{\mathrm{s}}=$ The volume of the sample $(\mathrm{mL})$

\section{RESULTS AND DISCUSSION}

\subsection{Moisture Content}

Table 4 shows the results of the moisture content of the rice residues. The moisture content was $4.72 \%$ for the long grain rice husk, $5.63 \%$ for the short grain rice husk, $4.60 \%$ for the cascara de arroz rice husk and $6.07 \%$ for the japonica rice husk. These values are lower than the value of $8.1 \%$ reported by Subramanian et al. (2011) for the rice husk from India, the value of $9.8 \%$ reported by Velez et al. (2009) for the rice husk from Colombia, the value of $10.7 \%$ reported by Zhou et al. (2009) for the rice husk from China, the values of $8.68-10.44 \%$ reported by Mansaray and Ghaly (1997) for the rice husks from Louisiana (USA) and Sierra Leone and the values of $9.8-10.7 \%$ reported by Casaca and Costa (2009) for the rice husks from Portugal. They are, however, higher than the value of $4.2 \%$ reported by Kalderis et al. (2008) for the rice husk from India.

The moisture content was $6.58 \%$ for the long grain rice straw, $6.92 \%$ for the short grain rice straw, $6.82 \%$ for the cascara de arroz rice straw and $6.89 \%$ for the japonica rice straw. These values are in the ranges of $2-10 \%$ reported by Chang et al. (2011) and 3-15\% reported by Chiueh et al. (2012) for the rice straws from Taiwan. They are, however, much lower than the values of $12.1-12.6 \%$ reported by Chou et al. (2009) for the rice straws from Taiwan and much higher than the values of 3-5\% reported by Park et al. (2011) for the rice straws from Japan. 
Table 4. Moisture content of rice residues

\begin{tabular}{lll}
\hline Rice residues & Variety & $\begin{array}{l}\text { Moisture } \\
\text { content }(\mathbf{\%})^{\mathrm{a}}\end{array}$ \\
\hline Husk & Long grain & 4.72 \\
& Short grain & 5.63 \\
& Cascara de arroz & 4.60 \\
Straw & Japonica & 6.07 \\
& Long grain & 6.58 \\
& Short grain & 6.92 \\
& Cascara de arroz & 6.82 \\
& Japonica & 6.89 \\
\hline
\end{tabular}

a: Average of three replicates

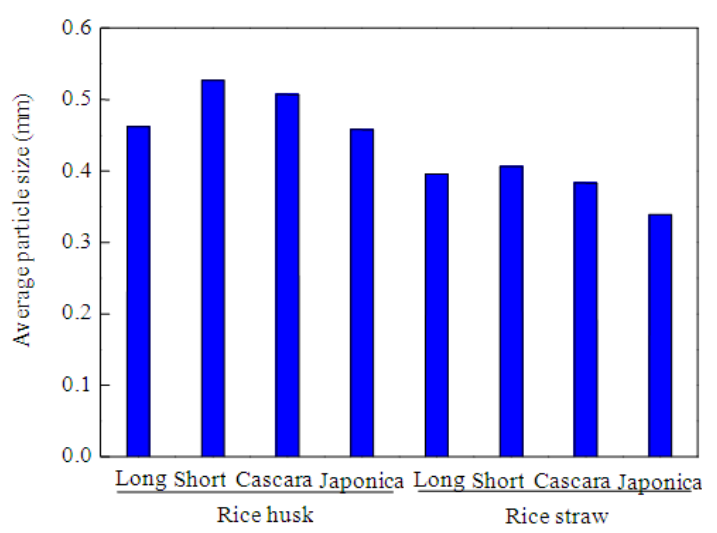

Fig. 5. Average particle size of rice husks and straws

Differences in moisture content could have resulted from using different collection, storage and drying procedures. For example, the samples used in this study were dried in an oven at $105^{\circ} \mathrm{C}$ for one day whereas the samples reported by Chou et al. (2009) were dried in air for two weeks and the samples reported by Park et al. (2011) were dried at $70^{\circ} \mathrm{C}$ for 5 days. For all rice varieties tested, the moisture content of the rice straw (6.58-6.92\%) was higher than these of the rice husk (4.60-6.07\%), which indicates that different parts of the rice plant maintain different moisture content.

The moisture content provides a medium for the transport of dissolved nutrients required for the metabolic and physiological activities of microorganisms in the solid fuels (Liang et al., 2003). Pommier et al. (2008) stated that an increase in moisture content showed a linear increasing effect on the biodegradation rate of organic material which resulted in the loss of solid fuels. The moisture content of rice residues also substantially affects its quality as a fuel source. Mansaray and Ghaly (1997) and Chen et al. (2009) reported that an increase in moisture content of the rice residues decreased their heating value, which in turn reduced the conversion efficiency and performance of the system, because a large amount of energy would be used for vaporization of the fuel moisture during the conversion processes.

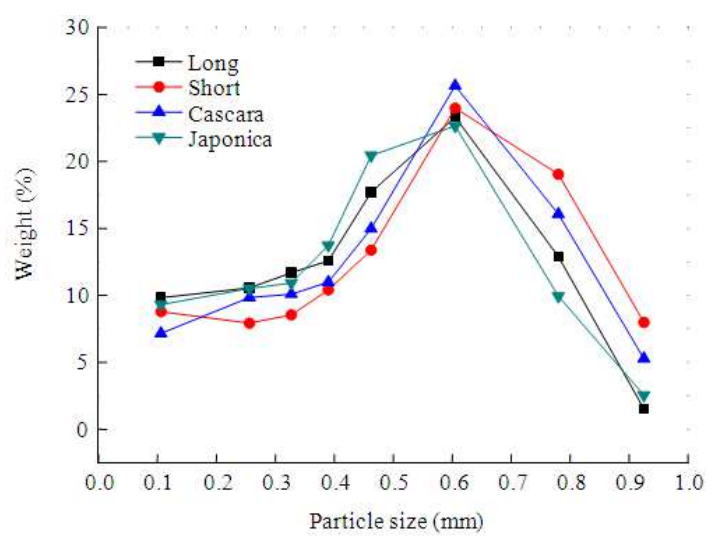

(a)

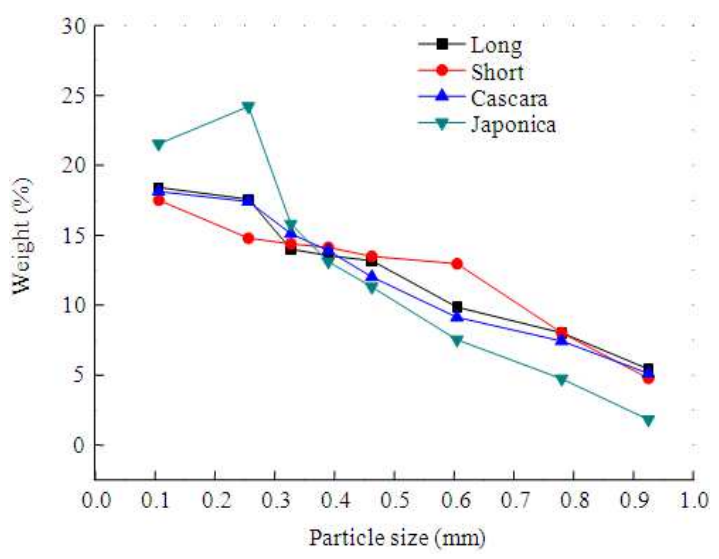

(b)

Fig. 6. Particle size distribution of rice husks and straws (a) Rice husks; (b) Rice straws

A dry material is thus preferred for efficient storage and combustion, whereas a certain amount of moisture in the fuel is beneficial for gasification or combustion (Shao et al., 2012; Kuprianov et al., 2010).

\subsection{Particle Size Distribution}

The results of the particle size distribution of rice residues are presented in Table 5. The majority (83.25$88.66 \%$ ) of rice husk particles were in the range of $0.212-$ $0.850 \mathrm{~mm}$. These values are within the range of $0.1-1 \mathrm{~mm}$ reported by Casaca and Costa (2009) for the rice husks from Portugal, the range of $0.075-3 \mathrm{~mm}$ reported by Subramanian et al. (2011) for the rice husk from India and the range of $0-10 \mathrm{~mm}$ reported by Fang et al. (2004) for the rice husk from China. However, the particle size range obtained in this study is higher than the range of $0.05-0.3$ $\mathrm{mm}$ reported by Kuo et al. (2011) for the rice husk from Taiwan and lower than the range of 1.40-2.36 mm reported by Mansaray and Ghaly (1997) for the rice husks from Louisiana (USA) and Sierra Leone. 
Table 5. Particle size distribution of rice residues Weight percentage (\%) ${ }^{\mathrm{a}}$

\begin{tabular}{|c|c|c|c|c|c|c|c|c|}
\hline \multirow[b]{2}{*}{ Size range $(\mathrm{mm})$} & \multicolumn{4}{|l|}{ Rice husks } & \multicolumn{4}{|l|}{ Rice straws } \\
\hline & Long grain & Short grain & Cascara & Japonica & Long grain & Short grain & Cascara & Japonica \\
\hline $0 \sim 0.212$ & 9.82 & 8.78 & 7.15 & 9.31 & 18.42 & 17.50 & 18.12 & 21.53 \\
\hline $0.212 \sim 0.300$ & 10.54 & 7.92 & 9.83 & 10.51 & 17.58 & 14.78 & 17.41 & 24.20 \\
\hline $0.300 \sim 0.355$ & 11.67 & 8.54 & 10.09 & 10.92 & 13.99 & 1438 & 15.11 & 1580 \\
\hline $0.355 \sim 0.425$ & 12.57 & 10.41 & 10.98 & 13.72 & 13.54 & 14.13 & 13.89 & 13.11 \\
\hline $0.425 \sim 0.500$ & 17.70 & 13.37 & 14.98 & 20.43 & 13.17 & 13.49 & 12.01 & 11.30 \\
\hline $0.500 \sim 0.710$ & 23.30 & 23.98 & 25.64 & 22.65 & 9.86 & 12.95 & 9.13 & 7.52 \\
\hline $0.710 \sim 0.850$ & 12.88 & 19.03 & 16.05 & 9.93 & 8.02 & 8.01 & 7.42 & 4.73 \\
\hline$>0.850$ & 1.52 & 7.97 & 5.28 & 2.53 & 5.42 & 4.76 & 5.11 & 1.81 \\
\hline
\end{tabular}

${ }^{\mathrm{a}}$ : Average of three replicates

Most particle sizes (76.16-77.74\%) of the rice straw samples were in the range of $0.212-0.850 \mathrm{~mm}$, which is within the range of $0-0.833 \mathrm{~mm}$ reported by Karimi et al. (2006) for the rice straw from Iran and the range of 0-4 $\mathrm{mm}$ reported by Chen et al. (2003) for the rice straw from the Netherlands. It is, however, higher than the range of 0 $0.3 \mathrm{~mm}$ reported by Asadullah et al. (2004) for the rice straw from Japan, the range of $0-0.5 \mathrm{~mm}$ reported by Sangnark and Noomhorm (2004) for the rice straw from Thailand, the range of $0.15-0.45 \mathrm{~mm}$ reported by Shi et al. (2012) for the rice straw from China and the range of $0.25-0.45 \mathrm{~mm}$ reported by Chou et al. (2009) for the rice straws from Taiwan and much lower than the range of 3-5 $\mathrm{mm}$ reported by Lei et al. (2010) for the rice straw from China and the range of 3-6 mm reported by Rashad et al. (2010) for the rice straw from Egypt.

The differences in particle size distributions resulted from using different pretreatment and grinding procedures of the samples. In our laboratory, the samples were ground through 3 sieves: a coarse sieve $(12.7 \mathrm{~mm})$, a 20 -mesh sieve $(0.85 \mathrm{~mm})$ and a 40 -mesh sieve $(0.425 \mathrm{~mm})$, whereas Mansaray and Ghaly (1997) ground their samples through 2 sieves: a 20 -mesh sieve $(0.85 \mathrm{~mm})$ and a $40-$ mesh sieve $(0.425 \mathrm{~mm})$. Kuo et al. (2011) milled the samples using balls in a ceramic milling jar. Lei et al. (2010) cut their samples, Rashad et al. (2010) chopped their samples, Sangnark and Noomhorm (2004) soaked their samples in water, Asadullah et al. (2004) used ball mill to grind their samples, Shi et al. (2012) milled their samples through 40-100 mesh sieves and Chou et al. (2009) milled their samples through 40-60 mesh sieves. The samples used in this study were ground though 20-40 mesh sieves.

Figure 5 shows the average particle size of rice husks and straws while Fig. $\mathbf{6}$ shows the particle size distribution. The average particle sizes for the husk and straw of the rice varieties long, short, cascara and japonica were 0.462 , $0.527,0.507$ and $0.458 \mathrm{~mm}$ and $0.396,0.406,0.383$ and $0.339 \mathrm{~mm}$, respectively. All the rice husk varieties had a normal distribution of particle size around the main value of $0.6 \mathrm{~mm}$. About $83.25-88.66 \%$ of the rice husk particles were in the range of $0.212-0.850 \mathrm{~mm}$ while the dust $(<0.212$ $\mathrm{mm})$ and large particles $(>0.850 \mathrm{~mm})$ were in the ranges of
$1.52-7.97 \%$ and $7.15-9.82 \%$, respectively. The particle size distribution for the rice straw showed a decreasing trend, the larger the particle size the higher was the weight percentage. About $76.16-77.74 \%$ of the particles were in the range of $0.212-0.850 \mathrm{~mm}$ and the dust $(<0.212 \mathrm{~mm})$ was in the range of $1.81-5.42 \%$. The ground rice straws had $17.50-21.53 \%$ smaller particles $(<0.212 \mathrm{~mm})$ which is higher than those of the ground rice husks $(7.15-9.82 \%)$. This indicates that different parts of rice plant had different particle size distributions even if they were processed by the same equipment using the same procedures. This may be the results of differences in the chemical compositions of rice husk and straw. The ash, lignin, holocellulose, cellulose, hemicellulose and extractive contents reported by Raveendran et al. (1995) for rice husk and straw were 23.5, $14.3,49.4,31.3,24.3$ and $8.4 \%$ and $19.8,13.6,52.3,37.0$, 22.7 and $13.1 \%$, respectively.

Ryu et al. (2006) stated that large particles are thermally thick thereby having slow devolatilization rate and more distributed heat transfer to the nearby particles. On the other hand, small particles of fuel may enhance the reaction area and result in high burning rates and ignition front speeds (Kwong et al., 2007). Small particle size can also significantly increase the bulk density of biofuels (Sangnark and Noomhorm, 2004) and eventually increase the energy density and reduce the cost of transport and storage (Chiueh et al., 2012; Deng et al., 2009). Size reduction therefore appears to be beneficial and important for pretreatment of biofuels before the utilization (Zhang and Zhang, 1999).

\subsection{Bulk Density}

Table 6 shows the bulk density of the rice residues. The average bulk density was $377.24 \mathrm{~kg} \mathrm{~m}^{-3}$ for the long grain rice husk, $331.59 \mathrm{~kg} \mathrm{~m}^{-3}$ for the short grain rice husk, $344.97 \mathrm{~kg} \mathrm{~m}^{-3}$ for the cascara de arroz rice husk and $380.54 \mathrm{~kg} \mathrm{~m}^{-3}$ for the japonica rice husk. These values are similar to the value of $348.8 \mathrm{~kg} \mathrm{~m}^{-3}$ reported by Velez et al. (2009) for the rice husk from Colombia, the value of $353 \mathrm{~kg} \mathrm{~m}^{-3}$ reported by Bishnoi et al. (2004) for the rice husk from India and are within the range of $100-400 \mathrm{~kg} \mathrm{~m}^{-3}$ reported by Sridhar et al. (1996) for the rice husk from India. 
Table 6. Bulk density of rice residues

\begin{tabular}{lll}
\hline Rice residues & Variety & Bulk density $\left(\mathrm{kg} \mathrm{m}^{-3}\right)^{\mathrm{a}}$ \\
\hline Husk & Long grain & 377.24 \\
& Short grain & 331.59 \\
& Cascara de arroz & 344.97 \\
Straw & Japonica & 380.54 \\
& Long grain & 166.29 \\
& Short grain & 162.03 \\
& Cascara de arroz & 177.23 \\
& Japonica & 194.48 \\
\hline
\end{tabular}

${ }^{\mathrm{a}}$ : Average of three replicates

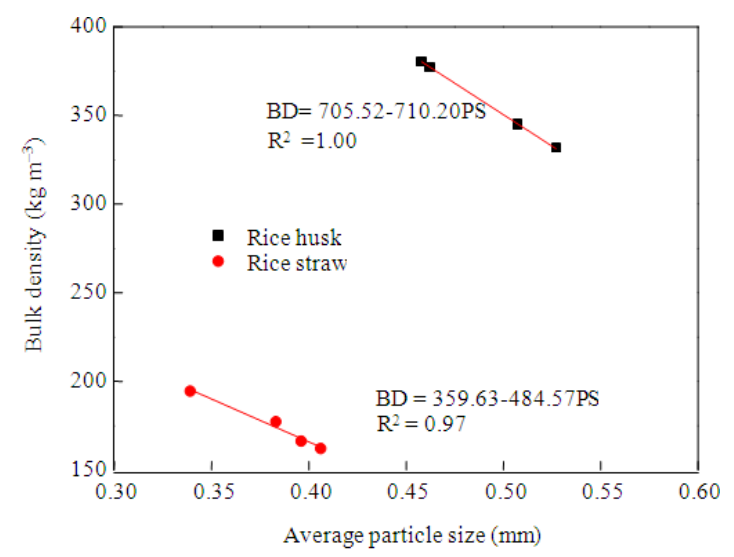

Fig. 7. Relationship between bulk density and average particle size

They are, however, lower than the value of $832 \mathrm{~kg} \mathrm{~m}^{-3}$ reported by Sahu et al. (2009) for the rice husk from India and higher than the values of $82.98-92.77 \mathrm{~kg} \mathrm{~m}^{-3}$ reported by Tirawanichakul et al. (2008) for the rice husk from Thailand, the values of $86-114 \mathrm{~kg} \mathrm{~m}^{-3}$ reported by Mansaray and Ghaly (1997) for the rice husks from Louisiana (USA) and Sierra Leone, the values of 72.2$293.4 \mathrm{~kg} \mathrm{~m}^{-3}$ reported by Angelova et al. (2011) for the rice husks from Bulgaria, the value of $122 \mathrm{~kg} \mathrm{~m}^{-3}$ reported by Fang et al. (2004) for the rice husk from China and the value of $126.56 \mathrm{~kg} \mathrm{~m}^{-3}$ reported by Subramanian et al. (2011) for the rice husk from India.

The average bulk density was $166.29 \mathrm{~kg} \mathrm{~m}^{-3}$ for the long grain rice straw, $162.03 \mathrm{~kg} \mathrm{~m}^{-3}$ for the short grain rice straw, $172.23 \mathrm{~kg} \mathrm{~m}^{-3}$ for the cascara de arroz rice straw and $194.48 \mathrm{~kg} \mathrm{~m}^{-3}$ for the japonica rice straw. These values are similar to the value of $177.6 \mathrm{~kg} \mathrm{~m}^{-3}$ reported by Yuan et al. (2012) for the rice straw from China and the value of $182 \mathrm{~kg} \mathrm{~m}^{-3}$ reported by Chiueh et al. (2012) for the rice straw from Taiwan and lower than the value of $227 \mathrm{~kg} \mathrm{~m}^{-3}$ reported by Kadam et al. (2000) for the rice straw from USA.

The bulk density values of rice straws are lower than those of rice husks. Higher ash and lignin contents in the rice husk may contribute to higher bulk density. The lignin and $\mathrm{SiO}_{2}$ reported by Soest (2006) for rice husk and straw were $160 \mathrm{~g} \mathrm{~kg}^{-1}$ and $230 \mathrm{~g} \mathrm{~kg}^{-1}$ and $52 \pm 16 \mathrm{~g} \mathrm{~kg}^{-1}$ and $130 \mathrm{~g} \mathrm{~kg}^{-1}$, respectively. The ash contents reported by $\mathrm{Xu}$ et al. (2012) for rice husk and straw were 22.1 and $14.6 \%$, respectively. The ash contents reported by Singha and Das (2011) for rice husk and straw were 11.80 and $9.40 \%$, respectively.

In this study, a negative linear relationship between the bulk density and the average particle size was observed for the rice husks and straws (Fig. 7), the larger the particle size the more void will be in the material and the lower the bulk density. These relationships can be described by the following Equation 4 and 5:

$\mathrm{BD}=705.52-710.20 \mathrm{PS}\left(\mathrm{R}^{2}=1.00\right.$ for rice husk $)$

$\mathrm{BD}=359.63-484.57 \mathrm{PS}(\mathrm{R} 2=0.97$ for rice straw $)$

Where:

$\mathrm{BD}=$ The bulk density $\left(\mathrm{kg} \mathrm{m}^{-3}\right)$

PS = The average particle size $(\mathrm{mm})$

The bulk density of rice husk affects its residence time in the reactor. Rozainee et al. (2008) stated that lower bulk density may result in lower conversion efficiency, as it gives rise to poor mixing characteristics and a nonuniform temperature distribution, both of which create unfavorable operating conditions of the thermochemical conversion systems. Densification of the rice husk and straw by briquetting or pelletizing can increase its density to more than $600 \mathrm{~kg} \mathrm{~m}^{-3}$ (Ryu et al., 2006) and densification of rice straw can increase its density to $270-730 \mathrm{~kg} \mathrm{~m}^{-3}$ (Kadam et al., 2000; Okasha, 2007). The major advantages of this technique include high volumetric density and energy content, lower transportation and storage costs and lower emissions during combustion (Ryu et al., 2006; Kadam et al., 2000; Khan et al., 2009). The high investment on equipment and energy input required for briquetting and pelletization are the major constrains of the densification process. However, the high cost of oil, current high demand for biomass utilization and technology improvement will make the process of densification more attractive.

\subsection{Porosity}

Table 7 shows the porosity of the rice residues. The average porosity was $64.20 \%$ for the long grain rice husk, $73.23 \%$ for the short grain rice husk, $70.45 \%$ for the cascara de arroz rice husk and $63.64 \%$ for the japonica rice husk. 
Table 7. Porosity of rice residues

\begin{tabular}{lll}
\hline Rice residues & Variety & Porosity $(\%)^{\mathrm{a}}$ \\
\hline Husk & Long grain & 64.20 \\
& Short grain & 73.23 \\
& Cascara de arroz & 70.45 \\
Straw & Japonica & 63.64 \\
& Long grain & 83.20 \\
& Short grain & 85.28 \\
& Cascara de arroz & 80.29 \\
& Japonica & 71.21 \\
\hline
\end{tabular}

${ }^{\mathrm{a}}$ : Average of three replicates

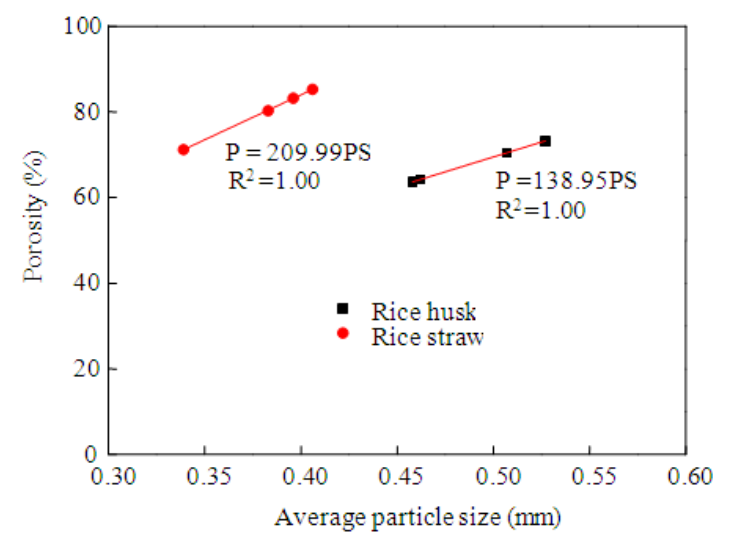

Fig. 8. Relationship between porosity and average particle size

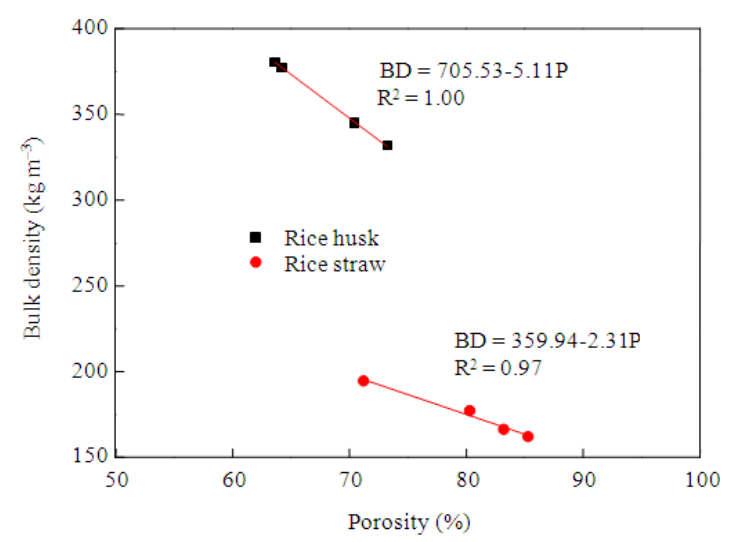

Fig. 9. Relationship between porosity and bulk density

These values are similar to the value of $64.08 \%$ (calculated from the apparent density and real density) presented by Velez et al. (2009) for the rice husk from Colombia but lower than the value of $75 \%$ reported by Subramanian et al. (2011) for the rice husk from India, the values of $75.4-75.6 \%$ represented by Zhou et al. (2009) and Fang et al. (2004) for the rice husks from China and the values of $94.22-98.42 \%$ reported by Tirawanichakul et al. (2008) for the rice husk from Thailand.

The average porosity was $83.20 \%$ for the long grain rice straw, $85.28 \%$ for the short grain rice straw, $80.29 \%$ for the cascara de arroz rice straw and $71.21 \%$ for the japonica rice straw. These values are higher than the value of $60 \%$ reported by Chen et al. (2003) for the rice straw from the Netherlands. This was mainly due to the smaller particle sizes of the sample (0-4 mm) compared to those obtained in the present study $(0-0.71 \mathrm{~mm})$. No other reports were found in the literature on the porosity of rice straw.

The porosity of biomass samples depends on a number of factors including particle size distribution, particle shape, shaking and pressing (Igathinathane et al., 2010). Differences in average particle size can result from using different procedures and will significantly affect the porosity. The samples in the present study were soaked in distilled water and the cylinder was gently rocked from side to side ten times to free trapped air bubbles whereas the samples presented by other researchers were saturated in salt solution for approximately 12-20 days.

Figure 8 shows a positive linear relationship between the porosity and the average particle size for rice husks and straws (the smaller the particle size the lower the porosity of the material). These relationships can be described by the following Equation 6 and 7:

$$
\begin{aligned}
& \mathrm{P}=138.95 \mathrm{PS}\left(\mathrm{R}^{2}=1.00 \text { for rice husk }\right) \\
& \mathrm{P}=209.99 \mathrm{PS}\left(\mathrm{R}^{2}=1.00 \text { for rice straw }\right)
\end{aligned}
$$

where, $\mathrm{P}$ is the porosity (\%)

A negative linear relationship between the porosity and the bulk density of the rice husks and straws was observed in this study (Fig. 9), the larger the porosity the lower the bulk density of the material. These relationships can be described by the following Equation 8 and 9:

$$
\begin{aligned}
& \mathrm{BD}=705.53-5.11 \mathrm{P}\left(\mathrm{R}^{2}=1.00 \text { for rice husk }\right) \\
& \mathrm{BD}=359.94-2.31 \mathrm{P}\left(\mathrm{R}^{2}=0.97 \text { for rice straw }\right)
\end{aligned}
$$

Igathinathane et al. (2010) and Hamel and Krumm (2008) stated that a decrease in the porosity will increase the interstitial airflow velocity and brings changes in heat and mass transfer conditions and ultimately influences the combustion parameters such as heat conductivity, burning rate, conversion efficiency and emissions. Briquetting or pelletizing can decrease the porosity of biomass samples. Igathinathane et al. (2010) reported the porosity values of $39.4-44.9 \%$ for cylindrical wood pellets. This is due to the fact that the cylindrical wood pellets are squeezed under pressure and heat and are, therefore, more compact (Igathinathane et al., 2010; Kaliyan and Morey, 2009; Demirbaş and Şahin, 1998). 


\subsection{Effect of Variety and Cultivation Conditions}

The results obtained from this study showed significant differences in the physical properties of the rice husks and straws collected from different countries (Egypt, Cuba and China) located in three different continents (Africa, south America and Asia). These differences may be due to variations in climatic conditions (temperature, precipitation and length of cultivation season), soil type (alluvial, luvisols and black), methods of cultivation (transplanting and seeding) and type of fertilizer used as shown in Table 2. Also, significant differences were observed among the varieties grown under same climatic conditions using same soil type and cultivation method as in the case of the long and short grain rice varieties of Egypt.

\section{CONCLUSION}

The physical properties of rice residues (husk and straw) obtained from three countries (Egypt, Cuba and China) in different continents (Africa, South America and Asia) were determined. These included moisture content, particle size distribution, bulk density and porosity. The moisture contents of rice husks and straws were in the ranges of $4.60-6.07 \%$ and $6.58-6.92 \%$, respectively. For all rice varieties tested, the moisture contents of the straws were higher than these of the husks. Most particle sizes of rice husks and straws were in the range of $0-0.850 \mathrm{~mm}$. All the rice husk varieties had a normal distribution of particle size around the main value of $0.6 \mathrm{~mm}$, while the particle size distribution for the rice straws showed a decreasing trend, the larger the particle size the higher was the weight percentage. The bulk density for rice husks and straws were in the ranges of $331.59-380.54 \mathrm{~kg} \mathrm{~m}^{-3}$ and $162.03-194.48 \mathrm{~kg} \mathrm{~m}^{-3}$, respectively. The bulk density values of rice straws were lower than those of rice husks. A negative linear relationship between the bulk density and the average particle size was observed for rice husks and straws. The porosity of rice husks and straws were in the ranges of $63.64-68.94 \%$ and $71.21-85.28 \%$, respectively. A positive linear relationship between the porosity and the average particle size was observed for rice husks and straws. The results obtained from this study showed significant differences in the physical properties of the rice husks and those of the rice straws indicating that different parts of rice plants had different physical properties. The results also showed significant differences among the rice residues collected from different countries located in three continents. These differences may be due to variations in climatic conditions, soil type, methods of cultivation and type of used fertilizer. Also, significant differences were observed among rice varieties as in the case of the long and short grain rice variety of Egypt, even though they were grown under the same climatic conditions using same soil type and cultivation method.

\section{ACKNOWLEDGEMENT}

The project was funded by National Science and Engineering Council (NSERC) of Canada. The authors would like to thank Mr. Rye Dube and Mr. Weida Shi for their technical support during the grinding experiments.

\section{REFERENCES}

Angelova, D., I. Uzunov, S. Uzunova, A. Gigova and L. Minchev, 2011. Kinetics of oil and oil products adsorption by carbonized rice husks. Chem. Eng. J., 172: 306-311. DOI: 10.1016/j.cej.2011.05.114

Asadullah, M., T. Miyazawa, S.I. Ito, K. Kunimori and M. Yamada et al., 2004. Gasification of different biomasses in a dual-bed gasifier system combined with novel catalysts with high energy efficiency. Applied Catalysis A: General, 267: 95-102. DOI: 10.1016/j.apcata.2004.02.028

Binod, P., R. Sindhu, R.R. Singhania, S. Vikram and L. Devi et al., 2010. Bioethanol production from rice straw: An overview. Bioresource Technol., 101: 4767-4774. DOI: 10.1016/j.biortech.2009.10.079

Bisaria, R., M. Madan and P. Vasudevan, 1997. Utilisation of agro-residues as animalfeed through bioconversion. Bioresource Technol., 59: 5-8. DOI: 10.1016/S0960-8524(96)00140-X

Bishnoi, N.R., M. Bajaj, N. Sharma and A. Gupta, 2004. Adsorption of $\mathrm{Cr}(\mathrm{VI})$ on activated rice husk carbon and activated alumina. Bioresource Technol., 91: 305-307. DOI: 10.1016/S0960-8524(03)00204-9

Casaca, C and M. Costa, 2009. $\mathrm{NO}_{\mathrm{x}}$ control through reburning using biomass in a laboratory furnace: Effect of particle size. Proc. Combust. Inst., 32: 2641-2648. DOI:10.1016/j.proci.2008.06.138

Chang, A.C.C., Y.H. Tu, M.H. Huang, C.H. Lay and C.Y. Lin, 2011. Hydrogen production by the anaerobic fermentation from acid hydrolyzed rice straw hydrolysate. Int. J. Hydrogen Energy, 36: 14280-14288. DOI:10.1016/j.ijhydene.2011.04.142

Chen, G., J Andries and H. Spliethoff, 2003. Catalytic pyrolysis of biomass for hydrogen rich fuel gas production. Energy Conv. Manage., 44: 2289-2296. DOI: $10.1016 / \mathrm{S} 0196-8904(02) 00254-6$

Chen, L., L. Xing and L. Han, 2009. Renewable energy from agro-residues in China: Solid biofuels and biomass briquetting technology. Renew. Sustain. Energy Rev., 13: 2689-2695. DOI: 10.1016/j.rser.2009.06.025 
Chiueh, P.T., K.C. Lee, F.S. Syu and S.L. Lo, 2012. Implications of biomass pretreatment to cost and carbon emissions: Case study of rice straw and Pennisetum in Taiwan. Bioresource Technol., 108: 285-294. DOI: 10.1016/j.biortech.2012.01.006

Chou, C.S., S.H. Lin and W.C. Lu, 2009. Preparation and characterization of solid biomass fuel made from rice straw and rice bran. Fuel Process. Technol., 90: 980-987. DOI: 10.1016/j.fuproc.2009.04.012

Delivand, M.K., M. Barz, S.H. Gheewala and B. Sajjakulnukit, 2011. Economic feasibility assessment of rice straw utilization for electricity generating through combustion in Thailand. Applied Energy, 88: 3651-3658. DOI: 10.1016/j.apenergy.2011.04.001

Demirbas, A and A. Sahin, 1998. Evaluation of biomass residue: 1 . Briquetting waste paper and wheat straw mixtures. Fuel Process. Technol., 55: 175-183. DOI: 10.1016/S0378-3820(98)00041-1

Deng, J., G.J. Wang, J.H. Kuang, Y.L. Zhang and Y.H. Luo, 2009. Pretreatment of agricultural residues for co-gasification via torrefaction. J. Analytical Applied Pyrolysis, 86: 331-337. DOI: 10.1016/j.jaap.2009.08.006

Dong, C.F., Q.S. Cai, C.L. Wang, J. Harada and K. Nemoto et al., 2008. QTL analysis for traits associated with feeding value of straw in rice (Oryza Sativa L.). Rice Sci., 15: 195-200. DOI: 10.1016/S1672-6308(08)60042-6

Fang, M., L. Yang, G. Chen, Z. Shi and Z. Luo et al., 2004. Experimental study on rice husk combustion in a circulating fluidized bed. Fuel Proces. Technol., 85: 1273-1282. DOI: 10.1016/j.fuproc.2003.08.002

FAO, 2011. Rice market monitor.

GS, 2011. Overview of the world's nations and their population.

Guo, Q., X. Chen and H. Liu, 2012. Experimental research on shape and size distribution of biomass particle. Fuel, 94: 551-555. DOI: 10.1016/j.fuel.2011.11.041

Haefele, S.M., Y. Konboon, W. Wongboon, S. Amarante and A.A Maarifat et al., 2011. Effects and fate of biochar from rice residues in rice-based systems. Field Crops Res., 121: 430-440. DOI: 10.1016/j.fcr.2011.01.014

Hamel, S and W. Krumm, 2008. Near-wall porosity characteristics of fixed beds packed with wood chips. Powder Technol., 188: 55-63. DOI: 10.1016/j.powtec.2008.03.011
Hernández, J.J., G. Aranda-Almansa and A. Bula, 2010. Gasification of biomass wastes in an entrained flow gasifier: Effect of the particle size and the residence time. Fuel Process. Technol., 91: 681-692. DOI: 10.1016/j.fuproc.2010.01.018

Igathinathane, C., J.S. Tumuluru, S. Sokhansanj, X. Bi and C.J. Lim et al., 2010. Simple and inexpensive method of wood pellets macro-porosity measurement. Bioresource Technol., 101: 65286537. DOI: 10.1016/j.biortech.2010.03.034

Kadam, K.L., L.H. Forrest and W.A. Jacobson, 2000. Ricestraw as a lignocellulosic resource: Collection, processing, transportation and environmental aspects. Biomass Bioenergy, 18: 369-389. DOI: 10.1016/S0961-9534(00)00005-2

Kalderis, D., S. Bethanis, P. Paraskeva and E. Diamadopoulos, 2008. Production of activated carbon from bagasse and rice husk by a single-stage chemical activation method at low retention times. Bioresource Technol., 99: 6809-6816. DOI: 10.1016/j.biortech.2008.01.041

Kaliyan, N and R.V. Morey, 2009. Factors affecting strength and durability of densified biomass products. Biomass Bioenergy, 33: 337-359. DOI: 10.1016/j.biombioe.2008.08.005

Karimi, K., G. Emtiazi and M.J. Taherzadeh, 2006. Ethanol production from dilute-acid pretreated rice straw by simultaneous saccharification and fermentation with Mucor indicus, Rhizopus oryzae and Saccharomyces cerevisiae. Enzyme Microbial. Technol., 40: 138-144. 10.1016/j.enzmictec.2005.10.046

Khan, A.A., W.D. Jong, P.J. Jansens and H. Spliethoff, 2009. Biomass combustion in fluidized bed boilers: Potential problems and remedies. Fuel Process. Technol., 90: 21-50. DOI: 10.1016/j.fuproc.2008.07.012

Kuo, H.P., S.M. Pan and H.T. Hsu, 2011. Comparisons of the hydrogen-rich syngas compositions from wet rice husk slurry steam reforming reactions using different catalysts. Biomass Bioenergy, 35: 30253031. DOI: 10.1016/j.biombioe.2011.04.005

Kuprianov, V.I., R. Kaewklum, K. Sirisomboon, P. Arromdee and S. Chakritthakul, 2010. Combustion and emission characteristics of a swirling fluidizedbed combustor burning moisturized rice husk. Applied Energy, 87: 2899-2906. DOI: 10.1016/j.apenergy.2009.09.009

Kwong, P.C.W., C.Y.H. Chao, J.H. Wang, C.W. Cheung and G. Kendall, 2007. Co-combustion performance of coal with rice husks and bamboo. Atmos. Environ., 41: 7462-7472. DOI: 10.1016/j.atmosenv.2007.05.040 
Liang, C., K.C. Das and R.W. McClendon, 2003. The influence of temperature and moisture contents regimes on the aerobic microbial activity of a biosolids composting blend. Bioresource Technol., 86: 131-137. DOI: 10.1016/S0960-8524(02)00153-0

Lei, Z., J. Chen, Z. Zhang and N. Sugiura, 2010. Methane production from rice straw with acclimated anaerobic sludge: Effect of phosphate supplementation. Bioresource Technol., 101: 43434348. DOI: 10.1016/j.biortech.2010.01.083

Mansaray, K.G and A.E. Ghaly, 1997. Physical and thermochemical properties of rice husk. Energy Sources, 19: 989-1004. DOI: 10.1080/00908319708908904

Natarajan, E., A. Nordin and A.N. Rao, 1998. Overview of combustion and gasification of ricehusk in fluidized bed reactors. Biomass Bioenergy, 14: 533546. DOI: 10.1016/S0961-9534(97)10060-5

Okasha, F., 2007. Staged combustion of rice straw in a fluidized bed. Exp. Thermal Fluid Sci., 32: 52-59. DOI: 10.1016/j.expthermflusci.2007.01.006

Park, J.Y., M. Ike, M. Arakane, R. Shiroma and Y. Li et al., 2011. DiSC (direct saccharification of culms) process for bioethanol production from rice straw. Bioresource Technol., 102: 6502-6507. DOI: 10.1016/j.biortech.2011.03.065

Pommier, S., D. Chenu, M. Quintard and X. Lefebvre, 2008. Modelling of moisture-dependent aerobic degradation of solid waste. Waste Manage., 28: 1188-1200. DOI: 10.1016/j.wasman.2007.05.002

Rashad, F.M., W.D. Saleh and M.A. Moselhy, 2010. Bioconversion of rice straw and certain agroindustrial wastes to amendments for organic farming systems: 1. Composting, quality, stability and maturity indices. Bioresource Technol., 101: 59525960. DOI: 10.1016/j.biortech.2010.02.103

Raveendran, K., A. Ganesh and K.C. Khilart, 1995. Influence of mineral matter on biomass pyrolysis characteristics. Fuel, 74: 1812-1822. DOI: 00162361(95)00142-5

Reidy, S., 2011. Global Rice Science Partnership seeks to increase productivity, improve efficiency of world staple crop.

Rozainee, M., S.P. Ngo, A.A. Salema, K.G. Tan and M. Ariffin et al., 2008. Effect of fluidising velocity on the combustion of rice husk in a bench-scale fluidised bed combustor for the production of amorphous rice husk ash. Bioresource Technol., 99: 703-713. DOI: 10.1016/j.biortech.2007.01.049
Ryu, C., Y.B. Yang, A. Khor, N.E. Yates and V.N. Sharifi et al., 2006. Effect of fuel properties on biomass combustion: Part I. Experiments-fuel type, equivalence ratio and particle size. Fuel, 85: 10391046. DOI: $10.1016 /$ j.fuel.2005.09.019

Sahu, J.N., S. Agarwal, B.C. Meikap and M.N. Biswas, 2009. Performance of a modified multi-stage bubble column reactor for lead(II) and biological oxygen demand removal from wastewater using activated rice husk. J. Hazard. Mater., 161: 317-324. DOI: 10.1016/j.jhazmat.2008.03.094

Sangnark, A and A. Noomhorm, 2004. Chemical, physical and baking properties of dietary fiber prepared from rice straw. Food Res. Int., 37: 66-74. DOI: 10.1016/j.foodres.2003.09.007

Shao, Y.Y., C. Xu, J. Zhu, F. Preto and J. Wang et al., 2012. Ash and chlorine deposition during cocombustion of lignite and a chlorine-rich Canadian peat in a fluidized bed-Effects of blending ratio, moisture content and sulfur addition. Fuel, 95: 2534. DOI: 10.1016/j.fuel.2011.12.020

Shi, L., S. Yu, F.C. Wang and J. Wang, 2012. Pyrolytic characteristics of rice straw and its constituents catalyzed by internal alkali and alkali earth metals. Fuel, 96: 586-594. DOI: 10.1016/j.fuel.2012.01.013

Singha, B and S.K. Das, 2011. Biosorption of Cr(VI) ions from aqueous solutions: Kinetics, equilibrium, thermodynamics and desorption studies. Colloids Surfaces B: Biointerfaces, 84: 221-232. DOI: 10.1016/j.colsurfb.2011.01.004

Soest, P.J.V., 2006. Rice straw, the role of silica and treatments to improve quality. Anim. Feed Sci. Technol., 130: 137-171. DOI: 10.1016/j.anifeedsci.2006.01.023

Sridhar, G., H.V. Sridhar, S. Dasappa, P.J. Paul and N.K.S. Rajan et al., 1996. Technology for gasifying pulverised bio-fuels including agricultural residues. Energy Sustain. Dev., 3: 9-18. DOI: 10.1016/S09730826(08)60586-4

Subramanian, P., A. Sampathrajan and P. Venkatachalam, 2011. Fluidized bed gasification of select granular biomaterials. Bioresource Technol., 102: 1914-1920. DOI: 10.1016/j.biortech.2010.08.022

Teghammar, A., K. Karimi, I.S. Horvath and M.J. Taherzadeh, 2012. Enhanced biogas production from rice straw, triticale straw and softwood spruce by NMMO pretreatment. Biomass Bioenergy, 36: 116-120. DOI: 10.1016/j.biombioe.2011.10.019

Tirawanichakul, S., Y. Tirawanichakul and E. Sniso, 2008. Paddy dehydration by adsorption: Thermophysical properties and diffusion model of agriculture residues. Biosyst. Eng., 99: 249-255. DOI: 10.1016/j.biosystemseng.2007.11.001 
USDA, 2011. Milled rice area harvested by country in $1000 \mathrm{HA}$.

Vadiveloo, J., B. Nurfariza and J.G. Fadel, 2009. Nutritional improvement of rice husks. Anim. Feed Sci. Technol., 151: 299-305. DOI: 10.1016/j.anifeedsci.2009.03.002

Velez, J.F., F. Chejne, C.F. Valdes, E.J. Emery and C.A. Londono, 2009. Co-gasification of Colombian coal and biomass in fluidized bed: An experimental study. Fuel, 88: 424-430. DOI: 10.1016/j.fuel.2008.10.018

Xu, W., Y.Y. Lo and S.A. Memon, 2012. Microstructure and reactivity of rich husk ash. Constr. Build. Mater., 29: 541-547. DOI: 10.1016/j.conbuildmat.2011.11.005

Yoon, S.J., Y.I. Son, Y.K. Kim and J.G. Lee, 2012. Gasification and power generation characteristics of rice husk and rice husk pellet using a downdraft fixed-bed gasifier. Renew. Energy, 42: 163-167. DOI: $10.1016 /$ j.renene. 2011.08 .028
Yuan, S., Z.H. Dai, Z.J. Zhou, X.L. Chen and G.S. Yu et al., 2012. Rapid co-pyrolysis of rice straw and a bituminous coal in a high-frequency furnace and gasification of the residual char. Bioresource Technol., 109: 188-197. DOI: 10.1016/j.biortech.2012.01.019

Zain, M.F.M., M.N. Islam, F. Mahmud and M. Jamil, 2011. Production of rice husk ash for use in concrete as a supplementary cementitious material. Constr. Build. Mater., 25: 798-805. DOI: 10.1016/j.conbuildmat.2010.07.003

Zhang, R and Z. Zhang, 1999. Biogasification of rice straw with an anaerobic-phased solids digester system. Bioresource Technol., 68: 235-245. DOI: 10.1016/S0960-8524(98)00154-0

Zhou, Z.Q., L.L. Ma, X.L. Yin, C.Z. Wu and L.C. Huang et al., 2009. Study on biomass circulation and gasification performance in a clapboard-type internal circulating fluidized bed gasifier. Biotechnol. Adv., 27: 612-615. DOI: 10.1016/j.biotechadv.2009.04.016 